AJSS, Vol. 3, No. 1, March 2004 - August 2004, pp.47-53

ISSN 0975-3311

https:/ / doi.org/ 10. 12725 / ajss .5.5

\title{
HEALTH CARE IN INDIA: OPPORTUNITIES, CHALLENGES AND STRATEGIES
}

T.D. Babu* and G. Jayabal**

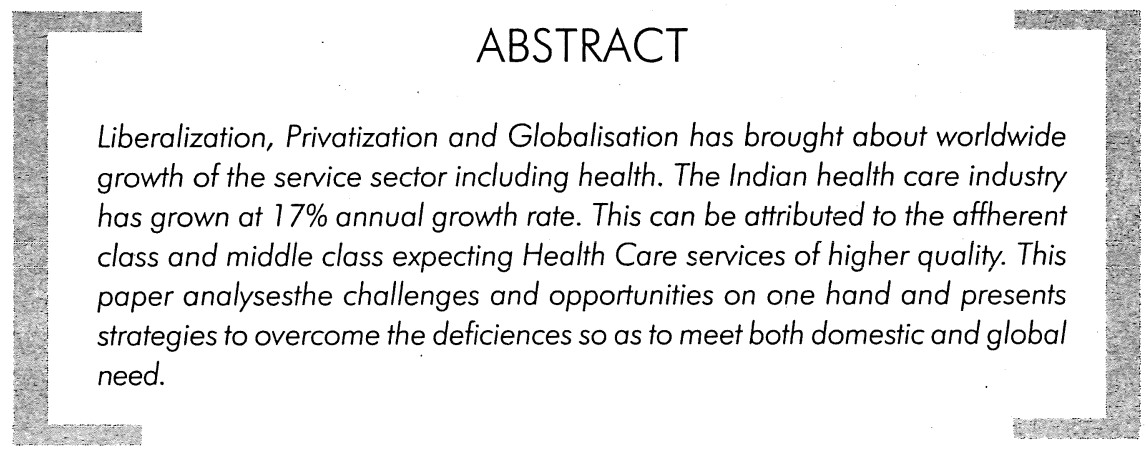

\section{Introduction}

\section{Role of Service Sector in Indian Economy}

Liberalization, Privatization and Globalization has brought about unprecedented and dynamic changes in the economic, trade, and industrial scenarios. Worldwide

* Dept. of Business Management, Near Nampally, Hyderabad.

** Dept. of Management, Alagappa Institute of Management, Alagappa University, Karaikudi 
the growth of service sector has been significant and is reflected in the contribution to GDP. and employment generation. The contribution of the services sector growth to the overall growth of the India's GDP increased from $43.7 \%$ to $51.2 \%$ from 1990-91 to 1998-99 (RBl annual report 1998-99). Growth of senvice industry can be attributed to the changing lifestyle, changing world, changing industrial economies, changing population and changing technology. Inspite of the pressure of political - legal, economic, social, technological and competitive forces on services, there has been an exponential growth of service sector at large. Service sector is very wide in its gamut, touching all the activities of human beings namely health, education, welfare, communication, travel, banking, professional services, insurance, advertising, crdit rating, information technology and so on and so forth. Hence in the future, the expansion of business and opportunities of employment are more and plenty in the private sector.

\section{Profile of Health Care Sector in India}

According to the Economic Times Health care 2001-02 Report, India's Healthcare (sector) industry grew at $13 \%$ per annum over the last decade and at present, is growing at $17 \%$ annually. Earlier reports of Mckinsey disclosed that the Health care industry was contributing $5.2 \%$ of the GDP of India. With hard work and collaboration among the government, and industry and insurance coverage, the contribution to GDP could go up to $6.2 \%$.

Indian Health care industry estimated to be around Rs. 100,000 crores presently and expected to reach Rs. 200,000 crores by 2012 with $17 \%$ annual growth rate. The growth has been attributed to the increasing affluent and more consumeroriented middle class expecting Health care services at higher levels of quality. The private sector plays significant role in the provision of health care services. On an average an Indian family is estimated to spend Rs. 10,000 per annum towards the medical expenses: The industry suffers from general infrastructural bottlenecks. The country lags behind international standards on basic health care infrastructure and facilities. India has 94 beds per 100,000 population as compared to the WHO norm of 333 beds per 100,000 population. Further the density of doctors is low (only 43 doctors for 100,000 population). And there is the high incidence of disease. According to the World Health Report 2000, India's health expenditure is $5.2 \%$ of its GDP. A study of government public health expenditure reveals that only $16 \%$ is allocated to primary care and $84 \%$ is allocated to secondary and tertiary care.

India has 503900 doctors, 7.37 Lakhs nurses, 162 medical colleges, 143 pharmacy colleges and 3.5 Lakhs chemists. There are around 15100 hospitals accounting 
for 9 Lakhs beds approximately. There is an extensive three tiered government health care infrastructure comprising 23,000 primary health centres, 137000 sub centres and 3000 community health centre. (OPPI, 2000 estimates). Government run hospitals and those operated by charities were main providers of subsidized health care till 1980s. For the last two decades, there has been mushrooming of corporate and privately run hospitals. The private sector accounts for $70 \%$ of primary medical care and $40 \%$ of all hospitals care in India. $80 \%$ of the medical personnel are employed in the private sector.

\section{Challenges and Opportunities before the Health Care Sector in India}

1. The demand-supply gap for health care delivery is large. In terms of number of hospital beds, India has less than one third of the WHO norm. As per the Mckinsey's Report 2002, India has 1.5 beds per 1,000 people while China, Brazil and Thailand have an average of 4.3 beds. WHO's report states that India needs to add 80,000 hospital beds each year to meet the demands of its population, of which 40,000 beds annually the private sector has to add.

2. In the US, it is generally observed that there are 100 categories of skilled people in a superspeciality hospital while in India there are just 60 categories observed by Dr. Ojha (Director - hospic, Mumbai)

3. Indian health care sector, with highly fragmented hospitals and health care systems, and the distribution of hospitals, is skewed. In Maharashtra, there are 3115 hospitals; Kerala 2040, Himachal Pradesh has ony 57 hospitals. The difference is primarily due to the difference in the extent of private sector participation in the health care sector. $90 \%$ of hospitals are owned by private sectors in the states like, Andhra Pradesh, Maharashtra, Gujarat and Kerala.

4. Health care is a business of soul and involves questions of life and death. Hospital venture suffers from long - gestation period. As per the area of specialization (cardiology/gastroenterology / eye treatment / cancer treatment) a 200 - 300 bedded hospital takes minimum of five years and maximum of seventeen years. Further the industry is capital intensive. Per bed project cost is estimated to be Rs. 4 Lakhs for a general hospital, Rs. 15 Lakhs for a secondary care hospital and Rs. 35 Lakhs for a tertiary (multi speciality) hospital.

5. Health care industry in India is lacking standardization, accreditation and sharing of information on management expertise. There is wide and significant scope for partnership in the field of health informatics. 
6. In India health insurance coverage is extremely low. It covers just 2.5 million of the population. Lack of adequate health insurance is an impediment to the growth of the health care industry. Even in the existing insurance products, the focus is more on dealing with infections rather than lifestyle diseases like diabetes, Cardio-vascular and nervous system disorders. Corporates need a vast health insurance base to bank on insurers need for large-scale corporatisation of health care to be viable as insurers. Insurers complain that medical fraud is deep rooted that they would go busy just settling claims. Mediclaim, the only product available, is still paying out more money than it receives as premium resulting in losses; Hence, foreign health insureres remain numb to the market. But Boston Consulting Group (BCG) estimated 315 million potential insurable lives.

7. There is a change in the socio-economic mix of people, with the growing middle class prepared to pay more for quality healthcare. There is a change in disease profile which results in higher growth of industry. Further Mckinsey reports that Indians will spend more on the treatment of lifestyle diseases than on vitamins and anti-infective treatment in the coming decade.

8. A majority depends on the private sector, including small clinics and nursing homes, resulting in poor quality of healthcare and high cost treatment. Further, the medical bill's; credibility due to lack of transparency is questioned.

9. Further the following are the opportunities

a) It is projected that 1.2 million cancer cases to be treated by 2011 .

b) It is projected that five million HIV-positive population of India in 2002.

c) It is estimated that about 18 out of every thousand people suffer from neurological disorders in India and

d) 47 million projected diabetic population in 2010 .

10. There is a tremendous stock of intellectual capital in Indian healthcare and state-of-the-art treatment. World class surgeries are available in India. But there is a dearth of qualified specialist nurses and paramedics and qualified hospital administrators. Trained nurses leave India due to attractive wages in the gulf countries and USA. Specialist nurse trading becomes vital as the number of single and multi-super specialty hospitals increase. However effectiveness is hampered and resulted in the growing need for professional hospital management, administration and executive development programs.

11. Health services are broadly classified into two: (a) Emergency medical services (EMS) and (b) Clinical based management. EMS and clinical based initiatives involve a host of products and services including education, consultancy, 
and equipment. Effective EMS demands advanced infrastructure and Supreme Court ruling has made it mandatory for hospitals to establish an effective clinical management system.

12. Malpractice events and claims and medical error not only endanger patients but also the trust of the people.

\section{Strategies to Overcome}

Building Healthcare as a global industry in India needs much effort and hard work from the part of the management and strategic and policy initiatives from the Government of India and the respective state governments. There, are some of the strategies recommended.

1. India would be unable to stand up to global standards unless there is focus on regulation and processes. Harpal Singh, Chairman, Fortis is of the opinion that there should be a joint effort between the industry and government. S.K. Venkataraman of Apollo hospitals, Chennai also opined that 15 year tax holiday and infrastructure status for Apollo's project in Srilanka enabled them to focus on marketing.

2. Redirection of the resources to cost effective solutions is suggested by Anil V. Kamath, V.P. Business development, Wockhardt hospitals Limited. The "feefor-service" model in the US has only escalated health care cost and India should not blindly follow the model. Rate restructuring of health care services is at the msot needed to tap the latest demand and penetrate the market. "One has to justify the rate" and the need of rationale in the rate structure is emphasized by Dr. Oiha, Director-hospic (hospital management consultancy firm) Mumbai. Compulsory insurance will build a provider network.

3. To tap the global market the following are the areas of assured potential:

- Planning and building healthcare facilities overseas.

- Managing healthcare facilities abroad.

- Off shore activities namely medical transcription, value-added services, software etc.

- Tele-medicine and body-shopping.

4. To sustain in the domestic markets in the following are important:

- Improvement in the area of hygiene and cleanliness (to attract global clientele).

- Building the Indian brand 
- Investing in the health care infrastructure of international standards.

- Inviting global health care brands to invest in the Indian facilities.

- Encourage domestic brands to set up facilities to target global market SAARC countries and Africa to begin with.

- Leverage on the current Indian software strength by focusing on health informatics.

- Medical tourism or health tourism has more potential (in the place of treatment tourism) which can highlight geriatric services, facilities for chronic illness, preventive care facilities, wellness programs, alternative medicine etc.

5. Development of a zone of hospitals catering mainly to the global market similar to technological parks, where the majority of companies are export oriented units.

6. Rating of hospitals stimulates hospitals to take up quality improvement initiatives provided it is done in an unbiased assessment by an external agency. Hospitals graded higher would have better facilities, superior quality levels and greater consistency in service delivery compared to those in lower grades. Healthcare grading is important for insurance companies and third party administrators.

7. As health consciousness spreads, preventive healthcare is becoming a big business and hence hospitals have to focus on these segments.

8. Effective maintenance of data about malpractice claims and medical error, will aid in identifying vulnerabilities and exposures to guide improvements and thereby reduce medical error and malpractice costs.

9. Health care organizations across the country should share data and information to help to identify best practices and reduce the cost of risk for patients.

10. Waste prevention means eliminating waste before it is created. It is a proven cost effective approach in many countries, which helps to improve the environment. Combined with a comprehensive recycling effort, hospitals can significantly reduce their waste.

\section{Conclusion}

Thus the above stated suggestions are to be kept in mind to tap the latent potential in both domestic and global market by both the entrepreneur/administrator of hospitals and the government. 


\section{References}

1. Ashish Gupta, (2002), 'The Rs. 80,000 crores question', Business Today, September 1st, 2002, pages $80-83$.

2. The Economic Times Healthcare Report 2001-2002.

3. "Healthcare in India: the road ahead" a joint study done by the CII \& Mckinsey \& company 2002.

4. Frederick Noronha, (2002), 'Indians will spend more on lifestyle diseases - a study', Indian Asian News Service.

5. 'Developing Indian healthcare Industry to match global standards;' www.expresshealthcaremanagement.com

6. 'Now, rating for hospitals', The (Hindu) Business Line, February 27, 2002.

7. Nilanjan Dey, (2002), "ICRA to foray into healthcare grading - reviews ties with hospital services consultancy', The Business Line, August 19th, 2002.

8. Premchand Palety, (2002), 'India's best hospitals', Outlook, July 1st, 2002, page 52.

9. Gina Singh (2003), 'Preventive health care', Business World, 311 st MArch, 2003, page 44.

10. Gina Singh, (2003) 'The super specialists', Business World, 17th Feb., 2003, page 63.

11. Proseniit Datta, (2003), 'The blues.....', Business World, 13th January, 2003, page 60.

12. Naazle Somjee, (2003), 'The safer chew', Business India, March 17th 2003, page 99. 